\title{
Insulin-like Growth Factor System Abnormalities in Hepatitis C-associated Osteosclerosis \\ Potential Insights into Increasing Bone Mass in Adults
}

\author{
Sundeep Khosla, ${ }^{\star}$ Ahmed A.K. Hassoun, ${ }^{*}$ Bonita K. Baker, ${ }^{\S}$ Frances Liu, ${ }^{\S}$ Nizar N. Zein, ${ }^{\ddagger}$ Michael P. Whyte," \\ Charles A. Reasner, " Todd B. Nippoldt, ${ }^{,}$Robert D. Tiegs, ${ }^{*}$ Raymond L. Hintz,, and Cheryl A. Conover* \\ *Endocrine Research Unit, Division of Endocrinology and Metabolism, ${ }^{\ddagger}$ Division of Gastroenterology, Mayo Clinic and Mayo \\ Foundation, Rochester, Minnesota 55905; ${ }^{\S}$ Department of Pediatric Endocrinology, Stanford University, Stanford, California 94305 ; \\ $\|$ Division of Bone and Mineral Diseases, Washington University School of Medicine, St. Louis, Missouri 63130; and "Division of \\ Endocrinology and Metabolism, The University of Texas, San Antonio, Texas 78285
}

\begin{abstract}
Hepatitis $\mathrm{C}$-associated osteosclerosis (HCAO) is a rare disorder characterized by a marked increase in bone mass during adult life. Despite the rarity of $\mathrm{HCAO}$, understanding the mediator(s) of the skeletal disease is of great interest. The IGFs-I and -II have potent anabolic effects on bone, and alterations in the IGFs and/or IGF-binding proteins (IGFBPs) could be responsible for the increase in bone formation in this disorder. Thus, we assayed sera from seven cases of HCAO for IGF-I, IGF-II, IGF-IIE (an IGF-II precursor), and IGFBPs. The distribution of the serum IGFs and IGFBPs between their ternary $(\sim 150 \mathrm{kD})$ and binary $(\sim 50 \mathrm{kD})$ complexes was also determined to assess IGF bioavailability.

HCAO patients had normal serum levels of IGF-I and -II, but had markedly elevated levels of IGF-IIE. Of the IGFBPs, an increase in IGFBP-2 was unique to these patients and was not found in control hepatitis $\mathrm{C}$ or hepatitis $B$ patients. IGF-I and -II in sera from patients with $\mathrm{HCAO}$ were carried, as in the case of sera from control subjects, bound to IGFBP-3 in the $\sim 150-\mathrm{kD}$ complex, which is retained in the circulation. However, IGF-IIE was predominantly in the $\sim 50-\mathrm{kD}$ complex in association with IGFBP-2; this complex can cross the capillary barrier and access target tissues. In vitro, we found that IGF-II enhanced by over threefold IGFBP-2 binding to extracellular matrix produced by human osteoblasts and that in an extracellular matrix-rich environment, the IGF-II/IGFBP-2 complex was as effective as IGF-II alone in stimulating human osteoblast proliferation. Thus, IGFBP-2 may facilitate the targeting of IGFs, and in particular IGF-IIE, to skeletal tissue in HCAO patients, with a subsequent stimulation by IGFs of osteoblast function. Our findings in HCAO suggest a possible means to increase bone mass in patients with osteoporosis. (J. Clin. Invest. 1998. 101:2165-2173.) Key words: dense bones - bone formation - osteoporosis - IGFBP-2 • IGF-IIE peptide
\end{abstract}

Address correspondence to Sundeep Khosla, Mayo Clinic, 200 First Street SW, 5-164 West Joseph, Rochester, MN 55905. Phone: 507284-3707. FAX: 507-255-4828. E-mail: Khosla@mayo.edu

Received for publication 7 July 1997 and accepted in revised form 13 March 1998.

The Journal of Clinical Investigation

Volume 101, Number 10, May 1998, 2165-2173

http://www.jci.org

\section{Introduction}

Hepatitis $\mathrm{C}$-associated osteosclerosis $(\mathrm{HCAO})^{1}$ is a recently described, rare syndrome characterized by a marked increase in skeletal mass in adults who are infected with the hepatitis $\mathrm{C}$ virus (1-8). Spine and hip bone mineral densities are elevated as much as twofold in these affected individuals, who represent the most dramatic example of acquired osteosclerosis in humans (3). Radiographs show dense bones in the appendicular and axial skeleton, with sparing of the calvarium and facial bones. Biochemical markers of bone formation are usually elevated, and transiliac bone biopsies generally show increased bone formation rates. Nevertheless, osseous tissue from these patients appears histologically to be of good quality with intact lamellar patterns, unlike the abnormal, rapidly remodeling woven bone found in patients with Paget bone disease (1-8). Although HCAO seems to be an extremely rare syndrome, an understanding of the mediator(s) of the increased skeletal mass is of great interest (9), because controlled stimulation of osteoblast function is sought after to treat metabolic bone diseases such as osteoporosis $(1-5,10)$.

To date, 10 cases of HCAO have been reported (1-8). However, it is apparent that only a small percentage of all patients infected with hepatitis $\mathrm{C}$ develop osteosclerosis, as skeletal radiographs of 107 randomly selected hepatitis $\mathrm{C}$-infected patients failed to show dense bones (11). Thus, although it is uncertain whether hepatitis $\mathrm{C}$ is the causative agent of the skeletal disease $(3,11,12)$, a plausible hypothesis is that either hepatitis $\mathrm{C}$ or another parenterally transmitted agent increases hepatic production of a growth factor(s) that stimulates osteoblast function $(1,10)$.

IGF-I and -II are important skeletal growth factors that are produced both by the liver and by osteoblasts and are thus potential candidates for mediating the increase in osteoblastic activity in $\operatorname{HCAO}(13,14)$. IGF-I and -II are synthesized as precursor forms with carboxy-terminal E-domain extensions (15, 16). These prohormones are then processed, by removal of the E-domain, into mature $\sim 7$-kD peptides normally present in the circulation $(17,18)$. IGF-II prohormone (IGF-IIE) appears to have biologic activity similar to IGF-II $(19,20)$, and increased circulating levels of $\sim 10-20-k D$ IGF-IIE produced by certain mesenchymal and epithelial tumors have been im-

1. Abbreviations used in this paper: ALS, acid labile subunit; HCAO, hepatitis $\mathrm{C}$-associated osteosclerosis; IGFBP, insulin-like growth factor binding protein; NICTH, nonislet cell tumor hypoglycemia; rh, recombinant human. 
plicated in the pathogenesis of nonislet cell tumor hypoglycemia (NICTH; 21-24).

The activities of the IGFs are modulated both systemically and locally by a family of high affinity IGF-binding proteins (IGFBPs), six of which have been characterized to date (13). The IGFBPs are structurally homologous yet functionally distinct (13). They serve a number of important roles, including transport of IGFs in the circulation, delivery of IGFs to target tissues, and modulation of cell responses to IGFs (13). 95\% of IGFs in the circulation are tightly bound to IGFBP-3 with an acid labile subunit (ALS) in a ternary complex of $\sim 150 \mathrm{kD}$. This complex is restricted to the vascular space and serves to limit bioavailability of IGFs to target tissues (25). Approximately $5 \%$ of IGFs circulated bind to IGFBP-1, -2 , and -4 in $\sim 50$-kD binary complexes that can cross the capillary barrier and may be responsible for targeting IGFs to specific tissues (25).

Given the importance of the IGFs in skeletal growth and differentiation, we studied the IGF/IGFBP system in 7 of the 10 HCAO cases reported to date (1-5), in comparison to four control groups: healthy age-matched individuals, hepatitis $\mathrm{C}$ patients without osteosclerosis, hepatitis $\mathrm{B}$ patients, and patients with Paget bone disease. In HCAO, we find specific abnormalities in the IGF/IGFBP system that could increase bioavailability of IGFs to skeletal tissue, causing increased bone formation.

\section{Methods}

Patients and control groups. After informed consent, overnight fasting serum samples were obtained from seven of the previously reported cases of HCAO (1-5). All patients had documented acquired osteosclerosis (assessed radiologically and histologically) and serological evidence of chronic hepatitis $\mathrm{C}$ infection, although none had symptomatic liver disease and the hepatitis $\mathrm{C}$ infection tended to be an incidental clinical finding. There were five men and two women aged 32-73 yr. Sera were kept either on dry ice or at $-70^{\circ} \mathrm{C}$ until analyzed. Control groups included normal healthy individuals $(n=9$, age range 36-71 yr), hepatitis $\mathrm{C}$ patients without clinical or radiologic evidence of osteosclerosis ( $n=9$, age range 22-70 yr), hepatitis B patients (as a control for an unrelated liver disease; $n=6$, age range 23$51 \mathrm{yr}$ ), and patients with Paget bone disease (as a control for increased bone formation unrelated to hepatitis $\mathrm{C}$ infection; $n=5$, age range 54-71 yr).

$I G F / I G F B P$ measurements. IGF-I and IGF-II were measured by specific RIA after separation from IGFBPs by G-50 acid chromatography as described previously (26). IGF-IIE was measured by a previously validated RIA (24) using an antibody generated against a synthetic 16-amino acid segment of the predicted IGF-II E-domain $\left(\mathrm{E}-\mathrm{II}_{69-84}\right) . \mathrm{E}_{-\mathrm{II}_{69-84}}$ was used as radioligand and for the standard curve. This assay is specific for proteins with the E-II domain and does not detect the mature form of IGF-II. IGFBP-3 levels were measured by RIA as previously described using covalent [ ${ }^{125}$ I]IGF-II: IGFBP-3 as tracer (27). IGFBP-2 levels were assayed by RIA with a polyclonal anti-IGFBP-2 antibody (1:2,000 final dilution) provided by Werner Blum (Tubingen, Germany). Recombinant human (rh) IGFBP-2 purchased from Austral (San Ramon, CA) was used for the tracer and the standard curve. IGFBP-1 was measured by a two-site immunoradiometric assay and ALS by immunosorbent assay (Diagnostic Systems Laboratories, Webster, TX).

Column chromatography. Sephadex G-50 column chromatography in acid was performed as previously described (24). Briefly, patient or normal serum $(1 \mathrm{ml})$ was fractionated on a $120-\mathrm{cm}$ G-50 Sephadex column (Pharmacia, Piscataway, NJ) in 1\% formic acid. 5 -ml fractions were collected, lyophilized, and then redissolved in
RIA buffer. For Superdex 200 (S-200) chromatography, a 120-cm S-200 (Pharmacia) column was equilibrated in $0.1 \mathrm{M}$ Tris/ $\mathrm{HCl}$ with $0.15 \mathrm{M} \mathrm{NaCl}, \mathrm{pH} 7.4$ buffer, and $0.5 \mathrm{ml}$ of each serum sample was fractionated at a flow rate of $0.5 \mathrm{~mL} / \mathrm{min}$. 2-ml fractions were collected, and the IGFs and IGFBPs assayed as described above. Columns were calibrated with aldolase $(158 \mathrm{kD})$, ovalbumin (43 $\mathrm{kD})$, myoglobin $(19 \mathrm{kD})$, cytochrome $c(12.4 \mathrm{kD})$, and IGF-I and -II $(\sim 7 \mathrm{kD})$.

Western ligand blotting. Western ligand blot analysis for IGFBPs was performed as previously described (28). Briefly, $1 \mu \mathrm{l}$ of serum or $50 \mu \mathrm{l}$ of extracellular matrix sample (see below) was separated by SDS-PAGE with a $7.5-15 \%$ linear gradient under nonreducing conditions. The separated proteins were electroblotted onto nitrocellulose filters, and the filters were then blocked, probed with ${ }^{125} \mathrm{I}$-labeled IGF-II overnight at $4^{\circ} \mathrm{C}$, and visualized by autoradiography according to the method of Hossenlopp et al. (29). Scanning densitometry and molecular size determinations were performed using an UltraScan XL laser densitometer and Gel-Scan XL software (Pharmacia LKB Biotechnology, Uppsala, Sweden).

IGFPB-2 binding to extracellular matrix. Binding assays were performed using extracellular matrix derived from normal adult human osteoblastic cells (30) or fetal human osteoblastic cells immortalized with a temperature-sensitive $\mathrm{T}$ antigen (31). Cells were grown to confluency in 24-well plates (Primera, Falcon Laboratories, Logan, UT). Monolayers were washed and the cells removed as described by Aria et al. (32). The extracellular matrix that remained on the plates was used for the binding studies. In one set of experiments, extracellular matrix was incubated overnight at $4^{\circ} \mathrm{C}$ with rhIGFBP-2 (500 ng/ $\mathrm{ml}$, kindly supplied by Sandoz Pharmaceuticals, Basel, Switzerland) without and with $400 \mathrm{ng} / \mathrm{ml}$ IGF-I, IGF-II, or insulin. Extracellular matrix proteins were extracted and IGFBP content determined by Western ligand blotting. In a second set of experiments, extracellular matrix-coated wells were incubated overnight at $4^{\circ} \mathrm{C}$ with ${ }^{125} \mathrm{I}$-labeled rhIGFBP-2 $(50,000 \mathrm{cpm} ; 5 \mu \mathrm{Ci} / \mu \mathrm{g})$ without and with unlabeled IGF-I, IGF-II, or insulin. Extracellular matrix was extracted and counted in a gamma counter (ICN Micromedic Systems, Huntsville, AL). Nonspecific binding was defined as the amount of ${ }^{125} \mathrm{I}$-rhIGFBP-2 bound in the presence of $400 \mathrm{ng} / \mathrm{ml}$ unlabeled IGFBP-2. Nonspecific binding was subtracted from total binding to determine specific binding.

Human osteoblast proliferation studies. Proliferation studies using normal adult human osteoblasts were performed as described previously by our laboratory $(33,34)$. In brief, adult human osteoblastic cells were plated in 24-well plates and grown for either $1 \mathrm{~d}$ or for $10 \mathrm{~d}$. Cells were washed and changed to serum-free medium without or with $10 \mathrm{nM}$ of IGF-II, IGFBP-2, or the combination. $\left[{ }^{3} \mathrm{H}\right]$ Thymidine incorporation was measured at 22-26 h.

Statistical analysis. Overall group differences were assessed using ANOVA. When the ANOVA was statistically significant $(P<0.05)$, individual comparisons were performed using nonpaired two-sided $t$ tests. Data are presented as mean \pm SEM.

\section{Results}

Serum levels of IGFs/IGFBPs/ALS. Table I presents serum levels of IGFs, IGFBPs, and ALS in the HCAO patients and the four control groups. Serum levels of IGF-I and -II were not altered in HCAO and were not significantly different among the groups. Immunoreactivity for the E-peptide domain of IGF-II was elevated $\sim 2$.6-fold in $\mathrm{HCAO}$, into the range of values previously reported for patients with NICTH using this assay (24). However, IGF-II E-domain levels were also elevated in hepatitis $\mathrm{C}$ patients without osteosclerosis, but not in hepatitis B patients. Among the viral hepatitis patients, therefore, IGF-II E-domain elevations were specific for the two groups of hepatitis $\mathrm{C}$ patients. However, this abnormality was not unique to the hepatitis $\mathrm{C}$ patients, because IGF-II 
Table I. Serum Levels of IGFs and IGFBPs in HCAO and Control Groups (Mean \pm SEM)

\begin{tabular}{|c|c|c|c|c|c|c|c|}
\hline & IGF-I & IGF-II & IFG-II E & IGFBP-1 & IGFBP-2 & IGFBP-3 & ALS \\
\hline & $\mu g / l i t e r$ & $\mu g / l i t e r$ & $\mu g / l i t e r$ & $\mu g / l i t e r$ & $\mu g / l i t e r$ & $\mu g / l i t e r$ & $\mu g / m l$ \\
\hline Normals $(n=9)$ & $228 \pm 27$ & $657 \pm 55$ & $2.7 \pm 0.1$ & $30 \pm 9$ & $377 \pm 44$ & $2274 \pm 195$ & $20.1 \pm 1.0$ \\
\hline $\operatorname{HCAO}(n=7)$ & $190 \pm 18$ & $505 \pm 60$ & $7.1 \pm 1.0^{*}$ & $52 \pm 11$ & $803 \pm 159^{\ddagger}$ & $1354 \pm 196^{\S}$ & $12.2 \pm 2.7^{\S}$ \\
\hline Hepatitis C controls $(n=9)$ & $207 \pm 20$ & $598 \pm 25$ & $5.4 \pm 0.2^{*}$ & $31 \pm 9$ & $353 \pm 61$ & $1505 \pm 121^{\S}$ & $10.9 \pm 1.6^{*}$ \\
\hline Hepatitis B controls $(n=6)$ & $195 \pm 35$ & $546 \pm 142$ & $2.3 \pm 0.2$ & $90 \pm 54$ & $320 \pm 32$ & $1595 \pm 269 \|$ & $11.2 \pm 3.1^{\S}$ \\
\hline Paget's disease $(n=5)$ & $129 \pm 6$ & $669 \pm 38$ & $6.7 \pm 0.2 *$ & $14 \pm 4$ & $291 \pm 75$ & $2364 \pm 328$ & $17.3 \pm 3.1$ \\
\hline ANOVA ( $P$ value $)$ & 0.13 & 0.42 & $<0.001$ & 0.21 & 0.001 & 0.004 & 0.01 \\
\hline
\end{tabular}

${ }^{*} P<0.001$ versus normals; ${ }^{\ddagger} P<0.02$ versus normals; ${ }^{\S} P<0.01$ versus normals; and ${ }^{\|} P=0.06$ versus normals.

E-domain levels were also elevated in patients with Paget bone disease.

The IGF-II E-domain immunoreactivity in the sera of the HCAO patients was further characterized using Sephadex G-50 acid chromatography. Data from two of these patients are shown in Fig. 1. The IGF-II E-domain immunoreactivity in the HCAO sera had a molecular mass of $\sim 10-20 \mathrm{kD}$, with some size heterogeneity, as has previously been reported for IGF-II prohormone $(20,23,35)$. There was no evidence for low molecular weight E-domain fragments in the sera of these patients. Similar molecular mass estimates of $\sim 15 \mathrm{kD}$ for the IGF-II E-domain immunoreactivity were obtained by immunoblotting HCAO sera with IGF-II antibody (data not shown). Thus, the IGF-II E-domain immunoreactivity in sera of HCAO patients corresponded to the intact IGF-II prohormone, IGF-IIE.
Table I also presents immunoassayable levels of IGFBP-1, IGFBP-2, IGFBP-3, and ALS in the HCAO and control groups. IGFBP-1 levels were not significantly different among the groups. IGFBP-3 and ALS levels were lower in the hepatitis $\mathrm{C}$ and $\mathrm{B}$ patients compared to either the normal subjects or the patients with Paget bone disease. The unique abnormality in the HCAO patients, however, was a marked increase in IGFBP-2 levels (Table I). The immunoassay data were confirmed by Western ligand blot analysis of HCAO versus normal sera (Fig. 2), which also demonstrated the significant increase in IGFBP-2 in these patients at the expected molecular size for the intact protein on SDS-PAGE $(\sim 34 \mathrm{kD})$. The Western ligand blot data were independently verified by immunoprecipitating with IGFBP-2 antibody (data not shown). Immunoreactive IGFBP-2 in HCAO sera was confirmed to be intact protein by Biogel P-60 acid chromatography (data not

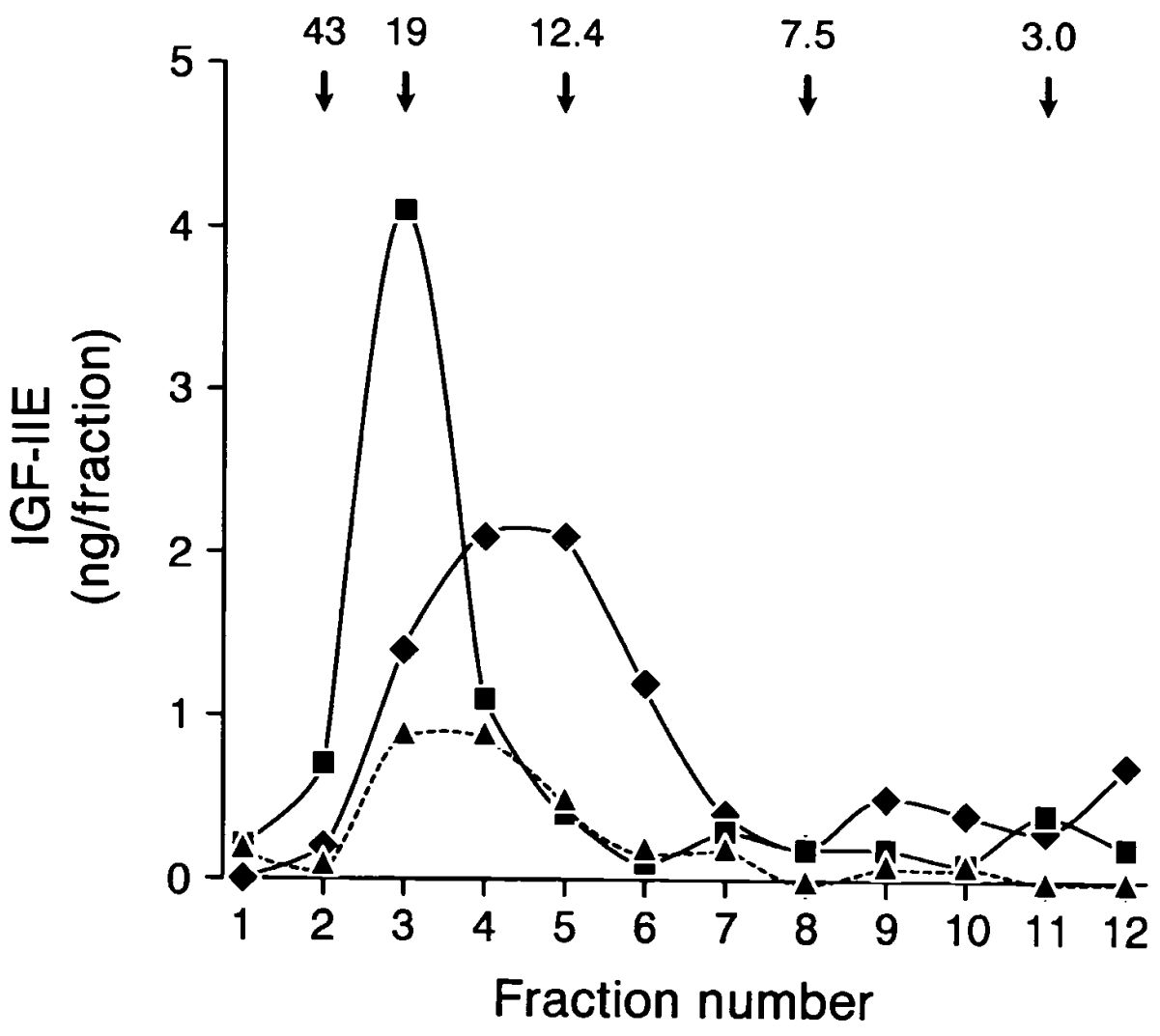

Figure 1. Sephadex G-50 chromatography at acid $\mathrm{pH}$. Sera of two HCAO patients $(\bullet, \mathbf{\square})$ and a pool of normal control serum $(\mathbf{\Lambda})$ were gel filtered on a Sephadex G-50 column in 1\% formic acid. Fractions were assayed for IGF-II E-peptide by RIA. The arrows indicate the elution volume of proteins used as molecular size markers, with the numbers indicating the size in $\mathrm{kD}$. 


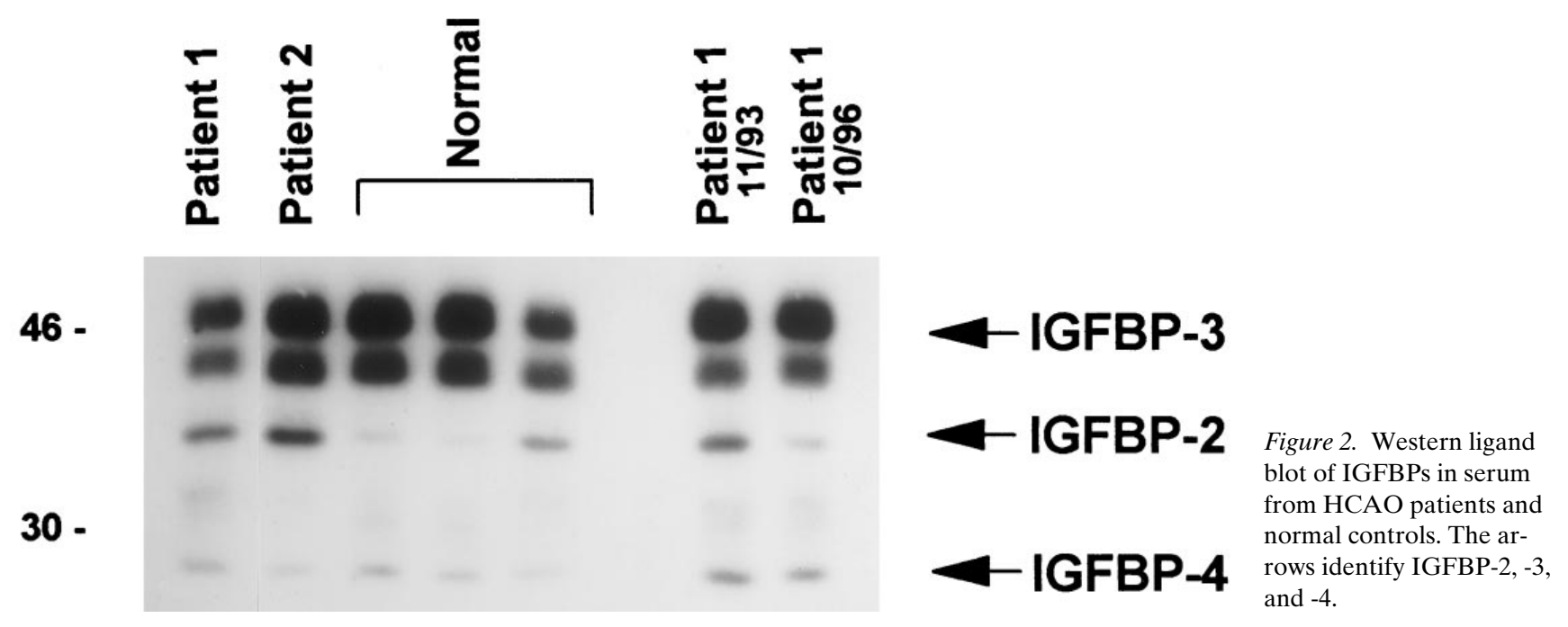

shown) as well as by nondenaturing S-200 chromatography (see Fig. 4). Whereas IGFBP-4 levels were not measured by immunoassay, Fig. 2 indicates that there was no apparent difference in IGFBP-4 levels between HCAO and normal subjects.

Fig. 2 also shows the decrease in serum IGFBP-2 levels between 1993 and 1996 in one of the HCAO patients who had clinical remission of bone pain over this time period (5). This remission was associated with a decrease in serum levels of liver enzymes (aspartate aminotransferase), as well as in markers of bone formation (alkaline phosphatase, osteocalcin). The biochemical changes were also associated with a marked decline in both serum IGFBP-2 and IGF-IIE to levels indistinguishable from the mean for the normal subjects (Table II). Treatment during this period consisted of subcutaneous calcitonin and bisphosphonates (intravenous pamidronate followed by oral etidronate) in an attempt to decrease bone turnover (5). Because increased bone turnover per se, as present in the Paget's patients, did not result in significant elevations in IGFBP-2 levels (Table I), the decline in IGFBP-2 levels over this time period was likely related to the course of the disease, perhaps due to remission of the liver disease, rather than to a nonspecific effect of a decrease in bone turnover.

Distribution of serum IGFs and IGFBPs between 150- and $50-k D$ complexes. In addition to measuring serum levels of the IGFs and IGFBPs, we also assessed the distribution of the

Table II. Changes Over Time in Serum Aspartate Aminotransferase (AST), Alkaline Phosphatase, Osteocalcin, IGF-IIE, and IGFBP-2 Levels in a Patient with HCAO

\begin{tabular}{lcc}
\hline & November 1993 & October 1996 \\
\hline AST, U/liter* & 68 & 34 \\
Alkaline phosphatase, U/liter & 3187 & 248 \\
Osteocalcin, $\mu$ g/liter & 219 & 60 \\
IGF-IIE, $\mu \mathrm{g} /$ liter & 7.2 & 1.6 \\
IGFBP-2, $\mu \mathrm{g} /$ liter & 862 & 372
\end{tabular}

* Reference range, 12-31 U/liter; ${ }^{*}$ Reference range, 98-257 U/liter; and ${ }^{\S}$ Reference range, 8.8-29.7 $\mu \mathrm{g} /$ liter.
IGFs bound to IGFBPs in the $\sim 150$ - and $\sim 50-\mathrm{kD}$ complexes in HCAO serum (Fig. 3). IGFBP-3 is the only binding protein that forms a $150-\mathrm{kD}$ ternary complex with IGF and ALS (25). As shown in Fig. $3 A$, most of the IGFBP-3 in the HCAO serum was found in the $150-\mathrm{kD}$ complex, as is the case for normal serum. Essentially all of IGF-I in HCAO serum was associated with IGFBP-3 in the $150-\mathrm{kD}$ complex, and this distribution of IGF-I did not differ between HCAO and normal serum (Fig. 3 $B)$. Nearly all of the IGF-II in normal serum was also in the $150-\mathrm{kD}$ fraction, and although most of the IGF-II in HCAO serum was in the $150-\mathrm{kD}$ fraction, there was some increase in IGF-II in the $50-\mathrm{kD}$ fraction in HCAO compared to normal serum (Fig. $3 C$ ).

All of the IGFBP-2 in the HCAO patients', as well as normal sera, was in the $50-\mathrm{kD}$ fraction. However, the absolute amount of IGFBP-2 was significantly increased in the patient sera (Fig. $4 A$ ). There was no evidence by S-200 chromatography of low molecular fragments of IGFBP-2 in HCAO sera. Moreover, as shown in Fig. $4 \mathrm{~B}$, the majority of IGF-IIE in the patient and control serum was also found in the $50-\mathrm{kD}$ complex, presumably in association with IGFBP-2, which is the principal component of this complex. In HCAO serum, there was some evidence for IGF-IIE in the $150-\mathrm{kD}$ complex as well.

In vitro studies on IGFBP-2 interactions with the extracellular matrix of human osteoblasts. The above in vivo data indicated not only that HCAO patients had an increase in both intact IGF-IIE and IGFBP-2, but also that the two proteins circulated together in the $50-\mathrm{kD}$ IGF/IGFBP complex. To determine if IGFBP-2 could facilitate the transport of IGF-II and/or IGF-IIE to bone matrix in these patients, we assessed whether the IGF/IGFBP-2 complex could bind to human bone matrix in vitro. As shown in Fig. 5, rhIGFBP-2 $(500 \mathrm{ng} / \mathrm{ml})$ was incubated overnight at $4^{\circ} \mathrm{C}$ with human osteoblast-derived extracellular matrix without and with $400 \mathrm{ng} / \mathrm{ml}$ of IGF-I, IGF-II, or insulin. The extracellular matrix was washed and rhIGFBP-2 binding determined by Western ligand blot of solubilized matrix. Extracellular matrix incubated without IGFs showed minimal binding of rhIGFBP-2 (lane $a$ ). However, in the presence of IGF-I or IGF-II, the binding of rhIGFBP-2 to extracellular matrix was significantly enhanced (lanes $e$ and $f$ ). By densitometry, rhIGFBP-2 binding to the osteoblast extracellular matrix 


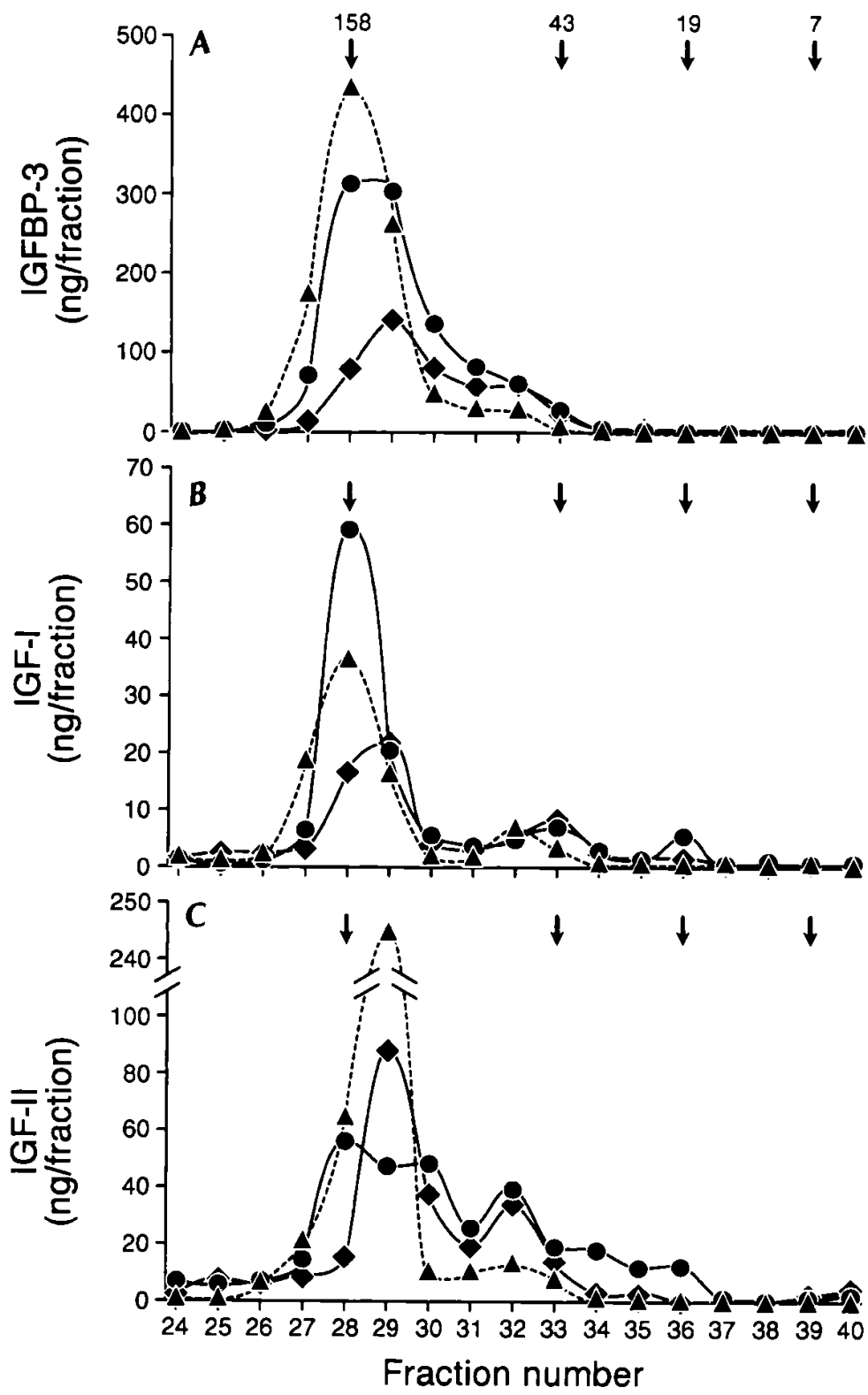

Figure 3. S-200 column chromatography at neutral $\mathrm{pH}$. Sera from two HCAO patients ( and $\bullet$ ) and a control subject $(\boldsymbol{\Delta})$ were filtered on a S-200 column. Fractions were assayed for IGFBP-3 $(A)$, IGF-I $(B)$, and IGF-II $(C)$. The arrows indicate the elution volume of proteins used as molecular size markers, with the numbers indicating the size in $\mathrm{kD}$. was increased twofold in the presence of IGF-I, whereas rhIGFBP-2 binding was increased over threefold in the presence of IGF-II. Insulin, which is structurally related to the IGFs but does not bind IGFBPs, did not enhance rhIGFBP-2 binding to the osteoblast extracellular matrix (lane $g$ ). In the absence of exogenous rhIGFBP-2, there was little or no endogenous IGFBP present in the osteoblast extracellular matrix (lanes $b-d)$. These findings were confirmed in another set of experiments that measured specific ${ }^{125}$ I-rhIGFBP-2 binding to the extracellular matrix produced by human osteoblasts. As shown in Table III, unlabeled IGF-I increased specific ${ }^{125} \mathrm{I}-$ rhIGFBP-2 binding to the osteoblast extracellular matrix by approximately twofold, whereas the same concentration of IGF-II increased ${ }^{125}$ I-rhIGFBP-2 binding by over fourfold. The converse experiment yielded similar findings, i.e., ${ }^{125}$ I-IGF-II alone did not bind extracellular matrix $(0.05 \pm 0.05 \%)$, whereas in the presence of unlabeled rhIGFBP-2, ${ }^{125}$ I-IGF-II specific binding was $2.86 \pm 0.10 \%(P<0.001)$.
Studies assessing IGFBP-2 effects on IGF-II stimulation of osteoblast proliferation. The above studies indicated that IGFBP-2 could facilitate the transport of IGF-II and/or IGF-IIE to bone matrix in HCAO patients. To test whether the IGF-II/IGFBP-2 complex could stimulate human osteoblast proliferation and to assess the potential role of extracellular matrix in modulating this effect, we compared IGF-II versus IGF-II + IGFBP-2 stimulation of human osteoblast proliferation either 1 or $10 \mathrm{~d}$ after plating. These cells have been shown to progressively produce extracellular matrix in vitro and, in fact, form mineralized nodules with continuous culture under appropriate conditions (30). Thus, the 1-d cultures represent a relatively extracellular matrix-poor environment, whereas the 10-d cultures represent a relatively extracellular matrix-rich environment. Under both conditions, IGF-II markedly stimulated osteoblast proliferation: the percent $\left[{ }^{3} \mathrm{H}\right]$ thymidine incorporation increased after stimulation with IGF-II from $0.12 \pm 0.003$ to $0.74 \pm 0.086 \%$ in the 1 -d cultures 


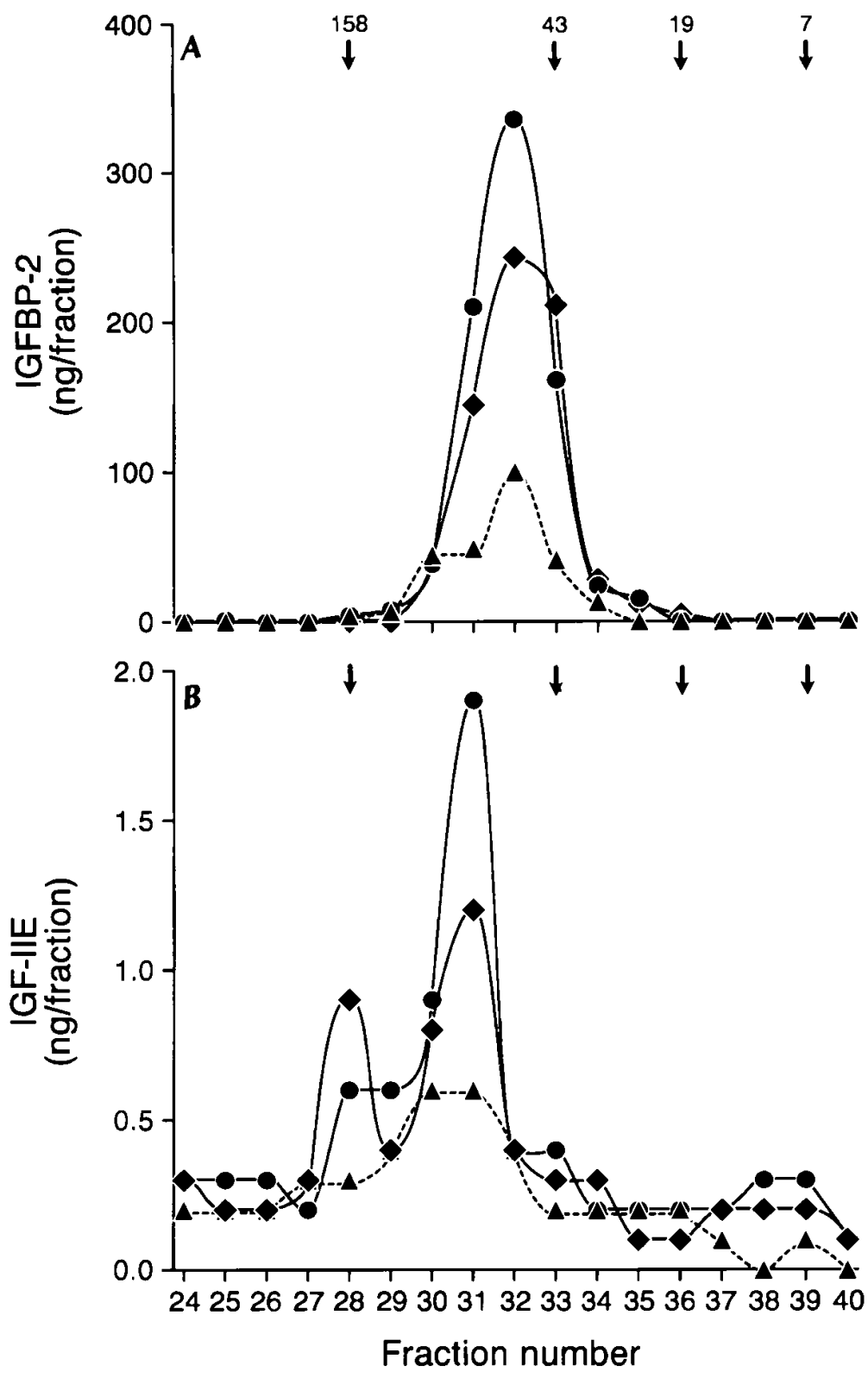

Figure 4. S-200 column chromatography at neutral $\mathrm{pH}$. Sera from two HCAO patients ( and $\bullet$ ) and a control subject $(\boldsymbol{\Lambda})$ were filtered on a S-200 column. Fractions were assayed for IGFBP-2 $(A)$ and IGF-IIE by RIA $(B)$ The arrows indicate the elution volume of proteins used as molecular size markers, with the numbers indicating the size in $\mathrm{kD}$.
$(P<0.005)$, and from $0.98 \pm 0.08$ to $2.06 \pm 0.12 \%(P<0.005)$ in the 10-d cultures. As shown in Fig. 6, however, whereas IGFBP-2 markedly inhibited (by 80\%) IGF-II stimulation of osteoblast proliferation in the 1-d cultures, the IGF-II/ IGFBP-2 complex was as effective as IGF-II in stimulating osteoblast proliferation in the 10-d cultures. IGFBP-2 alone had no effect on osteoblast proliferation under either condition (data not shown).

\section{Discussion}

Our studies demonstrate that HCAO, which is characterized by a marked increase in bone mass in adult life (1-8), is associated with elevated serum levels of IGF-IIE and IGFBP-2, with little or no alteration in IGF-I and -II levels or in their serumbinding profiles. Our longitudinal data spanning $3 \mathrm{yr}$ in one of the patients provide support for a cause-and-effect relation- ship between the elevated IGFBP-2 and IGF-IIE levels and the increase in bone formation. In addition, our in vitro studies show that IGF-II promotes the binding of rhIGFBP-2 to the extracellular matrix produced by human osteoblasts, and that in the presence of this extracellular matrix, the IGF-II/IGFBP-2 complex is as effective as IGF-II alone in stimulating osteoblast proliferation. Taken together, these data provide a potential mechanism for the targeting of IGFs to bone in HCAO, with a subsequent stimulation of osteoblast function.

Increases in both IGFBP-2 and IGF-IIE may be required for the stimulation of bone formation observed in HCAO patients. Thus, patients with hepatitis $\mathrm{C}$ but without osteosclerosis or patients with Paget bone disease had elevated IGF-IIE immunoreactivity but normal IGFBP-2 levels. IGFBP-2 levels are elevated after long-term fasting (35), in association with certain tumors (36), and in advanced cirrhotic liver disease (37). However, none of these conditions are associated with 
Table III. Specific ${ }^{125}$ I-labeled rhIGFBP-2 Binding to the Extracellular Matrix of Human Osteoblasts

\begin{tabular}{lc}
\hline & Percent specific binding \\
\hline${ }^{125}$ I-labeled rhIGFBP-2 alone & $0.73 \pm 0.08$ \\
${ }^{125}$ I-labeled rhIGFBP-2 + IGF-I & $1.31 \pm 0.11^{*}$ \\
${ }^{125}$ I-labeled rhIGFBP-2 + IGF-II & $3.13 \pm 0.30^{\ddagger}$
\end{tabular}

$* P=0.01$ versus ${ }^{125} \mathrm{I}$-labeled rhIGFBP-2 alone; and ${ }^{\ddagger} P=0.002$ versus ${ }^{125}$ I-labeled rhIGFBP-2 alone.

osteosclerosis as found in the HCAO patients. Finally, as part of the present study, we tested the hepatitis $\mathrm{C}$ genotype of four of the seven HCAO patients, and failed to observe a common genotype or novel strain of hepatitis $\mathrm{C}$ (data not shown).

It should be noted that the measurements of IGF-IIE in serum $(\sim 10-20 \mathrm{kD})$ were based on standard curves using the E-II ${ }_{69-84}$ fragment $(1.8 \mathrm{kD})$. Furthermore, although the antibody generated against $\mathrm{E}-\mathrm{II}_{69-84}$ specifically recognizes the IGF-IIE prohormone, it does not appear to have full access to this epitope in the larger IGF-IIE precursor form $(24,38)$. A recombinant IGF-IIE that consists of IGF-II plus the first 21 amino acids of the E-peptide domain is only $3-17 \%$ as effective an antigen as the E- $\mathrm{II}_{69-84}$ peptide in the IGF-II E-domain RIA $(24,38)$. Thus, on a molar basis, conservative estimates of circulating levels of intact IGF-IIE in HCAO patients would equal or exceed levels of IGFBP-2 $(\sim 24 \mathrm{nM})$.

The only other known disorder associated with both IGFBP-2 and IGF-IIE elevations is NICTH (22, 23, 25). NICTH patients develop severe hypoglycemia, and although bone mass or bone turnover have not been assessed in these individuals, they have not been reported to have osteosclerosis. Conversely, none of the patients with HCAO has had clinically evident hypoglycemia. Indeed, two of the HCAO patients had diabetes mellitus and received therapy with either an oral agent or with insulin $(5,8)$, and serum-fasting glucose concentrations in at least six of the patients have not been low (Whyte, M.P., unpublished data).

The primary cause of hypoglycemia in NICTH appears to

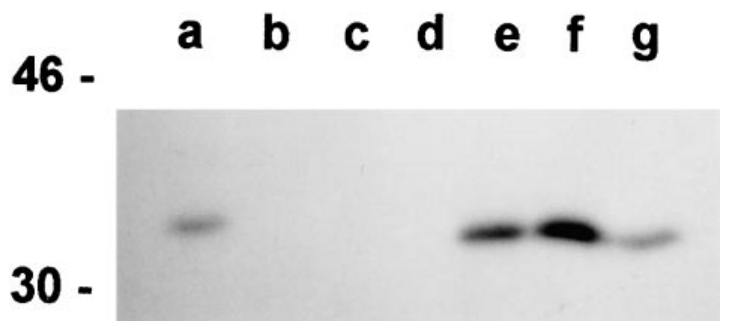

Figure 5. Binding of rhIGFBP-2 to extracellular matrix produced by human osteoblasts. Extracellular matrix was prepared from confluent human osteoblast cultures as described in Methods. Binding was carried out overnight at $4^{\circ} \mathrm{C}$, and IGFBP associated with the extracellular matrix determined by Western ligand blotting. Lane $a$ : exogenous rhIGFBP-2 alone; lane $b$ : exogenous IGF-I alone; lane $c$ : exogenous IGF-II alone; lane $d$ : exogenous insulin alone; lane $e$ : rhIGFBP-2 + IGF-I; lane $f$ : rhIGFBP-2 + IGF-II; lane $g$ : rhIGFBP-2 + insulin. Migration positions of molecular size markers (in $\mathrm{kD}$ ) are indicated on the left.

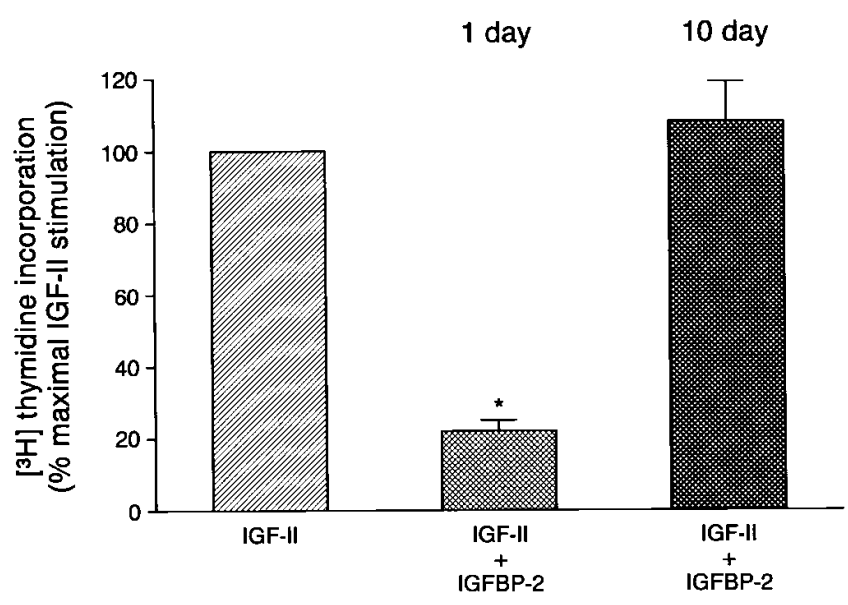

Figure 6. Effects of IGFBP-2 on IGF-II (both at $10 \mathrm{nM}$ ) stimulation of osteoblast proliferation in cells cultured either for 1 or $10 \mathrm{~d}$ before stimulation with IGF-II or IGF-II + IGFBP-2. $\left[{ }^{3} \mathrm{H}\right]$ Thymidine incorporation was determined as described in Methods. Data are expressed as the percent of maximal IGF-II stimulation (mean \pm SEM of three experiments). $* P<0.001$ versus IGF-II alone.

be the effect of tumor-derived IGF-IIE to directly and indirectly impair formation of the 150-kD ternary IGF/IGFBP-3/ ALS complex (i.e., by decreasing growth hormone and growth hormone-dependent ALS) $(22,23,25)$. In contrast, formation of the $150-\mathrm{kD}$ complex is not impaired in HCAO, with all of IGF-I and the majority of IGF-II remaining tightly bound to IGFBP-3 in the ternary complex, as in the case of normal serum. It is attractive to speculate that if, in HCAO, IGF-IIE and IGFBP-2 are produced by the same tissue (i.e., the liver) and rapidly form a complex, then the normal IGF/IGFBP pattern might not be disturbed, explaining an absence of hypoglycemia.

Our studies also demonstrate that the IGFBP-2 and IGFIIE in HCAO sera circulate together in a 50-kD complex. Several lines of evidence suggest that in this form, IGFBP-2 may facilitate the transport of IGF-IIE or IGF-II to skeletal tissue. Prosser et al. (39) have shown that the concomitant infusion of IGFBP-2 with IGF-I or -II in goats increased the clearance of IGF-I and -II, and at the same time reduced the transfer of IGFs into breast milk. They postulated that IGFBP-2 facilitates the transit of the IGFs out of the circulation, and away from the mammary epithelium, potentially towards some other tissue. The findings in the HCAO patients and our in vitro data suggest that this other tissue may well be the skeleton. Our demonstration that IGFs, and especially IGF-II, enhance IGFBP-2 binding to the extracellular matrix produced by human osteoblasts provides a potential mechanism for the selective transport of IGF-IIE (and possibly IGF-II) to the bone matrix of HCAO patients. Our in vitro studies are similar to recent observations of Arai et al. (32), who showed that the IGF/IGFBP-2 complex was able to bind the extracelluar matrix produced by fibroblasts. These investigators further demonstrated that binding of IGFBP-2 was principally to glycosaminoglycans, which are abundant in the bone matrix (32).

We also found that under conditions in which extracellular matrix is present, the IGF-II/IGFBP-2 complex is as effective as IGF-II in stimulating osteoblast proliferation. In contrast to 
our findings, several previous studies (40-43) indicate that IGFBP-2 can inhibit IGF action. There are, however, important differences between these studies and our in vivo and in vitro findings. All of the previous studies demonstrating an inhibitory effect of IGFBP-2 on IGF-I stimulation of osteoblast function used a 10-fold or greater molar excess of IGFBP-2 relative to IGF-I (40-43). Our findings suggest that circulating levels of intact IGF-IIE in HCAO patients would equal or exceed levels of IGFBP-2; hence, IGFBP-2 would not be in significant molar excess in HCAO patients. In the in vitro study in Fig. 6, we used an equimolar amount of IGFBP-2 and IGF-II, and IGFBP-2 was not inhibitory in the 10-d cultures. This is, in fact, consistent with previous studies in the rat fetal calvarial system, where equimolar amounts of IGFBP-2 did not inhibit IGF-I action (40). Thus, both the concentration of IGFBP-2 used and the presence or absence of extracellular matrix appear to be important factors in determining IGFBP-2 effects on IGF bioavailibility. A similar situation appears to be present in the case of IGFBP-3, which can inhibit IGF action (44), but IGFBP-3 at low concentrations (45) or cell-associated IGFBP-3 (46) is not inhibitory for IGF-I effects. In addition, IGFBP-5 binding to extracellular matrix results in decreased affinity of IGFBP-5 for IGFs, thus increasing the bioavailability of IGFs (47). Clearly, more studies are needed to better define the role of extracellular matrix in modulating the effects of IGFBP-2 on IGF action.

Finally, our studies have obvious potential implications for the treatment of osteoporosis $(3,10,12)$. Whereas several antiresorptive drugs, including estrogen, calcitonin, bisphosphonates, and selective estrogen receptor modulators are now available to treat osteoporosis, the ability to achieve large, sustained increases in bone mass remains an elusive goal. As noted earlier, HCAO is associated with marked increases in bone mass in adult life. Our data indicate that these increases in bone mass may be related to specific abnormalities in the IGF/IGFBP system. However, the notion of using IGFs to treat osteoporosis is not a novel one $(48,49)$. Previous studies in humans using IGF-I treatment have found increases in serum levels of markers of bone formation $(48,49)$. However, this approach is limited by the multiple systemic effects of IGF-I, including hypoglycemia. In an attempt to circumvent this problem, recent animal studies have used a combination of IGF-I and IGFBP-3, thus permitting administration of higher doses of IGF-I, and some increase in bone formation indices was noted $(50,51)$. Our findings with the HCAO patients, however, suggest that even more efficient transfer of IGFs to the skeleton could potentially be accomplished using IGFBP-2. If further studies validate this hypothesis, the insights provided by this rare but fascinating disorder may lead to the development of novel strategies to not just prevent, but actually reverse the loss of bone in patients with osteoporosis.

\section{Acknowledgments}

We would like to thank Laurie Bale for technical assistance, Roberta Soderberg for assistance with the handling of the serum samples, and Tufia Haddad for help with preparation of the figures. In addition, we thank B.L. Riggs and L.J. Melton III for helpful discussions and input.

This study was supported in part by research grants AG-04875 (S. Khosla), DK 43258 (C.A. Conover), and RR 00036 (M.P. Whyte) from the National Institutes of Health (Bethesda, MD).

\section{References}

1. Villareal, D.T., W.A. Murphy, S.L. Teitelbaum, M.Q. Arens, and M.P. Whyte. 1992. Painful diffuse osteosclerosis after intravenous drug abuse. Am. J. Med. 93:371-381.

2. Beyer, S.H., A.M. Parfitt, M.S. Shih, Q. Anderson, and H. Heath III. 1990. Idiopathic acquired diffuse osteosclerosis in a young woman. J. Bone Miner. Res. 5:1257-1263.

3. Whyte, M.P., S.L. Teitelbaum, and W.R. Reinus. 1996. Doubling skeletal mass during adult life: the syndrome of diffuse osteosclerosis after intravenous drug abuse. J. Bone Miner. Res. 11:554-558.

4. Whyte, M.P., and C.A. Reasner. 1997. Hepatitis C-associated osteosclerosis after blood transfusion. Am. J. Med. 102:219-220.

5. Hassoun, A., T.B. Nippoldt, R.D. Tiegs, and S. Khosla. 1997. Hepatitis $\mathrm{C}$-associated osteosclerosis: an unusual syndrome of acquired osteosclerosis in adults. Am. J. Med. 103:70-73.

6. Diamond, T., and B. Depczynski. 1996. Acquired osteosclerosis associated with intravenous drug use and hepatitis C infection. Bone. 19:679-683.

7. Bergman, D., T.L. Einhorn, and G. Forster. 1996. Stone bone syndromediffuse sclerosis of bone: a newly described clinical disorder. Endocr. Prac. 2:296.

8. Shaker, J.L., W.R. Reinus, and M.P. Whyte. 1998. Hepatitis C-associated osteosclerosis: late onset after blood transfusion in an elderly woman. J. Clin. Endocrinol. Metab. 83:93-98.

9. Cheng, S.-L., F. Leeanda, L.V. Avioli, and M.P. Whyte. 1996. Hepatitis C-associated osteosclerosis: search for a circulating osteoinductive factor. $J$. Bone Miner. Res. 11(Suppl. 1):S256. (Abstr.)

10. Khosla, S., A. Hassoun, and H. Heath III. 1995. Osteosclerosis in intravenous drug abusers. The Endocrinologist. 5:339-343.

11. Beyer, S.H., Q. Anderson, A.M. Parfitt, and H. Heath III. 1994. Diffuse osteosclerosis in intravenous drug abusers (letter). Am. J. Med. 95:660-662.

12. Whyte, M.P., W.A. Murphy, D. Villareal, S.L. Teitelbaum, and M. Arens. 1994. Osteosclerosis in intravenous drug abuse (reply letter). Am. J. Med. 95:661-662.

13. Conover, C.A. 1996. The role of insulin-like growth factors and binding proteins in bone cell biology. In Principles of Bone Biology, 1st edition. J.P. Bilezikian, L.G. Raisz, and G.A. Rodan, editors. Academic Press, San Diego, CA. 607-618.

14. LeRoith, D. 1997. Insulin-like growth factors. N. Engl. J. Med. 336:633-640. 15. Rotwein, P. 1986. Two insulin-like growth factor-I messenger RNAs are expressed in human liver. Proc. Natl. Acad. Sci. USA. 83:77-81.

16. Bell, G.I., J.P. Merryweather, R. Sanchez-Pescador, M.M. Stempien, L. Priestley, and J. Scott. 1984. Sequence of a cDNA clone encoding human preproinsulin-like growth factor II. Nature. 310:775-777.

17. Rinderknecht, E., and R.E. Humbel. 1978. The amino acid sequence of human insulin-like growth factor I and its structural homology with proinsulin. J. Biol. Chem. 253:2769-2776.

18. Rinderknecht, E., and R.E. Humbel. 1978. Primary structure of human insulin-like growth factor II. FEBS Lett. 89:283-286.

19. Gowan, L.K., B. Hampton, D.J. Hill, R.J. Schlueter, and J.F. Perdue. 1987. Purification and characterization of a unique high molecular weight form of insulin-like growth factor II. Endocrinology. 121:449-458.

20. Valenzano, K.J., E. Heath-Monnig, S.E. Tollefsen, M. Lake, and P. Lobel. 1997. Biophysical and biological properties of naturally occurring high molecular weight insulin-like growth factor II variants. J. Biol. Chem. 272:48044813 .

21. Daughaday, W.H., M.A. Emmanuele, M.H. Brooks, A.L. Barbato, M. Kapadia, and P. Rotwein. 1988. Synthesis and secretion of insulin-like growth factor II by a leiomyosarcoma with associated hypoglycemia. N. Engl. J. Med. 319:1434-1440.

22. Zapf, J., E. Futo, M. Peter, and E.R. Froesch. 1992. Can "big" insulinlike growth factor II in serum of tumor patients account for the development of extrapancreatic tumor hypoglycemia? J. Clin. Invest. 90:2574-2584.

23. Baxter, R.C. 1996. The role of insulin-like growth factors and their binding proteins in tumor hypoglycemia. Horm. Res (Basel). 46:195-201.

24. Liu, F., B.K. Baker, D.R. Powell, and R.L. Hintz. 1993. Characterization of proinsulin-like growth factor-II E-region immunoreactivity in serum and other biological fluids. J. Clin. Endocrinol. Metab. 76:1095-1100.

25. LeRoith, D., D. Clemmons, P. Nissley, and M.M. Rechler. 1992. Insulinlike growth factors in health and disease. Ann. Intern. Med. 116:854-862.

26. Powell, D.R., R.G. Rosenfeld, B.K. Baker, F. Liu, and R.L. Hintz. 1986 Serum somatomedin levels in adults with chronic renal failure: the importance of measuring insulin-like growth factor (IGF-I) and IGF-II in acid chromatographed uremic serum. J. Clin. Endocrinol. Metab. 63:1186-1192.

27. Liu, F., R.C. Baxter, and R.L. Hintz. 1992. Characterization of the high molecular weight insulin-like growth factor complex in term pregnancy serum. J. Clin. Endocrinol. Metab. 75:1261-1267.

28. Hassager, C., L.A. Fitzpatrick, E.M. Spencer, B.L. Riggs, and C.A Conover. 1992. Basal and regulated secretion of insulin-like growth factor binding proteins in osteoblast-like cells is cell line specific. J. Clin. Endocrinol. Metab. 75:228-233.

29. Hossenlopp, P., D. Seurin, B. Segovia-Quinson, S. Hardouin, and M. Binoux. 1986. Analysis of serum insulin-like growth factor binding proteins us- 
ing Western blotting: use of the method for titration of the binding proteins and competitive binding studies. Anal. Biochem. 154:138-143.

30. Robey, P.G., and J.D. Termine. 1985. Human bone cells in vitro. Calcif. Tissue Int. 37:453-460.

31. Harris, S.A., R.J. Enger, B.L. Riggs, and T.C. Spelsberg. 1995. Development and characterization of a conditionally immortalized human fetal osteoblastic cell line. J. Bone Miner. Res. 10:178-186.

32. Aria, T., W.J. Busby, and D.R. Clemmons. 1996. Binding of insulin-like growth factor (IGF) I or II to IGF-binding protein-2 enables it to bind heparin and extracellular matrix. Endocrinology. 137:4571-4575.

33. Conover, C.A. 1991. A unique receptor-independent mechanism by which insulinlike growth factor I regulates the availibility of insulinlike growth factor binding proteins in normal and transformed human fibroblasts. J. Clin. Invest. 88:1354-1361.

34. Durham, S.K., M.C. Kiefer, B.L. Riggs, and C.A. Conover. 1994. Regulation of insulin-like growth factor binding protein 4 by a specific insulin-like growth factor binding protein 4 proteinase in normal human osteoblast-like cells: implication in bone cell physiology. J. Bone Miner. Res. 9:111-117.

35. Clemmons, D.R., D.K. Snyder, and W.H. Busby. 1991. Variables controlling the secretion of insulin-like growth factor binding protein-2 in normal human subjects. J. Clin. Endocrinol. Metab. 73:727-733.

36. Mohnike, K., U. Kluba, W.F. Blum, V. Aumann, P. Vorwerk, and U. Mittler. 1995. Serum concentrations of insulin-like growth factors (IGF)-I and IGF-II and of IGF binding proteins (IGFBP)-2 and IGFBP-3 in 49 children with ALL, NHL or solid tumors. Klin. Paediatr. 207:225-229.

37. Scharf, J.G., F. Schmitz, J. Frystyk, C. Skjaerbaek, H. Moesus, W.F. Blum, G. Ramadori, and H. Hartmann. 1996. Insulin-like growth factor-I serum concentrations and patterns of insulin-like growth factor binding proteins in patients with chronic liver disease. J. Hepatol. 25:689-699.

38. Tally, M., U. Eriksson, M. Thoren, K. Brismar, and K. Hall. 1994. Immunoreactive proinsulin-like growth factor-II levels in healthy subjects, patients with growth hormone deficiency, and patients with type I diabetes: effects of insulin-like growth factor-I and insulin. J. Clin. Endocrinol. Metab. 79:15761581.

39. Prosser, C.G., and J. Schwander. 1996. Influence of insulin-like growth factor-binding protein-2 on plasma clearance and transfer of insulin-like growth factors-I and -II from plasma into mammary-derived lymph and milk of goats. J. Endocrinol. 150:121-127.

40. Feyen, J.H.M., D.B. Evans, C. Binkert, G.F. Heinrich, S. Geisse, and H.P. Kocher. 1991. Recombinant human [ $\mathrm{cys}^{281}$ insulin-like growth factor-binding protein 2 inhibits both basal and insulin-like growth factor I-stimulated proliferation and collagen synthesis in fetal rat calvaria. J. Biol. Chem. 266:19469-
19474.

41. Raisz, L.G., P.M. Fall, B.Y. Gabbitas, T.L. McCarthy, B.E. Kream, and E. Canalis. 1993. Effects of prostaglandin $\mathrm{E}_{2}$ on bone formation in cultured fetal rat calvaria: role of insulin-like growth factor-I. Endocrinology. 133:15041510 .

42. Delany, A.M., S. Rydziel, and E. Canalis. 1996. Autocrine down-regulation of collagenase-3 in rat bone cultures by insulin-like growth factors. Endocrinology. 137:4665-4670.

43. Kream, B.E., S. Tetradis, D. Lafrancis, P.M. Fall, J.H.M. Feyen, and L.G. Raizs. 1997. Modulation of the effects of glucocorticoids on collagen synthesis in fetal rat calvaria by insulin-like growth factor binding protein-2. $J$. Bone Miner. Res. 12:889-895.

44. Schmid, C., J. Rutishauser, I. Schlapfer, E.R. Froesch, and J. Zapf. 1991. Intact but not truncated insulin-like growth factor binding protein-3 (IGFBP-3) blocks IGF-I-induced stimulation of osteoblasts. Control of IGF signaling to bone cells by IGFBP-3 proteolysis. Biochem. Biophys. Res. Commun. 179:579-585.

45. Ernst, M., and G.A. Rodan. 1990. Increased activity of insulin-like growth factor (IGF) in osteoblastic cells in the presence of growth hormone $(\mathrm{GH})$ : positive correlation with the presence of the GH-induced IGF-binding protein BP-3. Endocrinology. 127:807-814

46. Conover, C.A. 1992. Potentiation of insulin-like growth factor (IGF) action by IGF binding protein-3: studies of underlying mechanism. Endocrinology. 130:3191-3199.

47. Jones, J.I., A. Gockerman, W.H. Busby, C. Camacho-Hubner, and D.R Clemmons. 1992. Extracellular matrix contains insulin-like growth factor binding protein-5: potentiation of the effects of IGF-I. J. Cell. Biochem. 121:679-687.

48. Ebeling, P.R., J.D. Jones, W.M. O'Fallon, C.H. Janes, and B.L. Riggs. 1993. Short-term effects of recombinant human insulin-like growth factor I on bone turnover in normal women. J. Clin. Endocrinol. Metab. 77:1384-1387.

49. Ghiron, L.J., J.L. Thompson, L. Holloway, R.L. Hintz, G.E. Butterfield, A.R. Hoffman, and R. Marcus. 1995. Effects of recombinant insulin-like growth factor-I and growth hormone on bone turnover in elderly women. J. Bone Miner. Res. 10:1844-1852.

50. Bagi, C.M., R. Brommage, L. Deleon, S. Adams, D. Rosen, and A. Sommer. 1994. Benefit of systemically administered rhIGF-I and rhIGF-I/IGFBP-3 on cancellous bone in ovariectomized rats. J. Bone Miner. Res. 9:1301-1312.

51. Narusawa, K., T. Nakamura, K. Suzuki, Y. Matsuoka, L.-J. Lee, H Tanaka, and Y. Seino. 1995. The effects of recombinant human insulin-like growth factor (rhIGF)-I and rhIGF-I/IGF binding protein-3 administration on rat osteopenia induced by ovariectomy with concomitant bilateral sciatic neurectomy. J. Bone Miner. Res. 10:1853-1864. 